International Journal of English Literature and Social Sciences
Vol-7, Issue-1; Jan-Feb, 2022
Journal Home Page Available: https://ijels.com/
Journal DOI: $10.22161 /$ ijels

Peer-Reviewed Journal

\title{
LSRW Skills: A Way to Enhance Communication
}

\author{
Robins D. John
}

Assistant Professor of English, Mar Gregorios College of Law, University of Kerala, Thiruvananthapuram, India Email: robinsdjohn@gmail.com

Received: 20 Nov 2021; Received in revised form: 27 Dec 2021; Accepted: 08 Jan 2022; Available online: 13 Jan 2022 C2022 The Author(s). Published by Infogain Publication. This is an open access article under the CC BY license (https://creativecommons.org/licenses/by/4.0/).

\begin{abstract}
Communication is an essential component for social interaction and personal growth. Communication is simply sharing information from one person to another. Four pillars of effective communication are Listening, Speaking, Reading and Writing. The article focuses on the basics of communication. It tries to delve deep into the various aspects of the communication process. Developing the LSRW skills would help one to enrich the overall quality of their lives. This article assists the readers to get acquaintance with the skills which are the key for building a better communication.
\end{abstract}

Keywords_Communication, Listening, Reading, Speaking and Writing.

"To effectively communicate, we must realize that we are all different in the way we perceive the world and use this understanding as a guide to our communication with others."- Tony Robbins

\section{INTRODUCTION}

Communication is the act of giving, receiving, and sharing information. The word Communication is derived from the Latin phrase, Communico or Communicare, which means 'to share'.Communication is simply the act of transferring information from one person to another. Every communication involves at least one sender, a message and a recipient. A communication therefore has three parts: the sender, the message, and the recipient. A message or communication is sent by the sender through a communication channel to a receiver, or to multiple receivers. Communication means sharing of information, messages, facts, feelings or ideas from one person to another.

The core Communicative skills are Listening, Speaking, Reading and Writing. To become an effective communicator, one must achieve all these four skills. These skills enrich a person in all wakes of his life. Communication is the most important factor that helps to build a better relationship with one another. Inorder to show case what you are and what another person is saying, you need to build a better communication. These four skills will fetch you to become a better person in different phases of one's life.

\section{Listening Skill}

The first and foremost skill for better communication is that one needs to develop the skill of listening. Listening is an art, where the listener pays attention to what he/she hears. Listening is an active process of receiving a message and the ability to comprehend what others are saying. If we pay a close attention to the meaning of what we hear, we can say that it's an active listening. So, it requires a conscious practice and active state in order to understand the matter being communicated and to give proper feedback to the message or the information. According to International Listening Association, "Listening is an active process of receiving, constructing meaning from, and responding to spoken and non-verbal messages". Good listening requires patience and a good state of mind. Good listening reduces misunderstandings and leads to better problem-solving skills. So, if a person receives carefully all the information given by the speaker, not only the words but also to his/her body language, gestures, and non-verbal signs and if they respond to the message that was being communicated we can say that it's an active listening. 
Some may be confused hearing to listening but both are distinctive terms. Hearing is a passive activity; it doesn't require any kind of skill as in listening. Hearing is just receiving some sounds to our ear drums. It can be anything; the sound of vehicles, sound of TV, music or anything.

\section{Stages of Listening}

Listening involves six stages. They are;

1. Hearing/Sensing: This is the first step in the process of listening. In this stage, the listener receives certain sound wave which falls to the eardrum.

2. Recognizing/Understanding: After sensing the sounds which falls to the eardrum, the listener identifies the speech patterns. A deliberate attempt is made by the listener to comprehend the word or symbols that we hear.

3. Interpreting: In this stage the listener starts decoding the message. Listener stick on their beliefs, attitudes, values to decode the message.

4. Evaluating: After understanding what the speaker says, the listener assesses the quality of the message.

5. Responding: Here the listener reacts to the message. He/she shows his/her rejection or acceptance or understanding or confusion through non-verbal, cues.

6. Remembering/Memorizing: The final stage of listening. In this stage we retain the information for our future reference.

\section{Barriers to Listening}

1. Uninterested Subject matter

This is one of the important barriers to listening. The listener may not be interested towards the subject. This lack of interest can act as a hindrance towards listening. The speaker may not show any kind of attempt to decipher the idea, since he/she has no interest towards the subject or content.

\section{False/Forged Attention}

Some listeners pretend that they are actively involved in the process of listening, but he/she may be preoccupied with something else. This is one of the most common barriers to active listening. They act and make the speaker believe that they are attentively listening.

3. Prejudiced Mentality/Premature Evaluation of the Subject

Before hearing or listening to the actual message, some evaluate or judge the message being communicated. They hastily conclude that the speaker is saying something else.

\section{Different Accent or Language Variety}

When a speaker uses different accent, which the listener feels hard to decipher is yet another important barrier of listening. The accents we Indians use might be different from that of an American.

\section{Lack of interest towards the Speaker}

Some may have some issue with the person who delivers the message; this can pose as a major problem in listening to that message.

\section{Physical Conditions}

The physical condition of the listener can create some kind of hindrance towards listening. This can be due to physical pain, exhaustion, noisy surroundings etc.

7. Lack of concentration

Some listeners easily get distracted since they have very poor listening skills.

\section{Techniques to be an Effective Listener}

Following are some of the important steps which can enrich one to be an effective listener:

1. Don't interrupt the speaker unnecessarily

2. Don't talk while the speaker is talking

3. Take down lecture notes while dealing with important topics

4. Ask questions to yourself

5. Establish a good eye contact with the speaker

6. Don't have a prejudiced mentality

\section{Speaking Skill}

Speaking is probably the language skill that most language learners wish to ((deliver perfectly) perfect as soon as possible. Speaking is an interactive process where information is shared, and if necessary, acted upon by the listener. So, it's important to develop both speaking and listening skills in order to communicate effectively.

Speaking is regarded as the one of the core skills, we learn as it helps us to share our thoughts feelings, ideas and emotions with others. Speaking skills can be further divided into formal and informal speaking skills, and we use both types in different contexts in our life.

Informal speaking skills are the skills for conversations with friends and family, helping us to form emotional connections. Formal speech, on the other hand, is necessary for workplaces, in presentations or for conversations with people you are not familiar with. 


\section{Reading Skill}

Reading is a process of looking at a series of written symbols and comprehending those symbols into words, sentences and paragraphs. It's a dynamic process to which reader communicates with the text to construct meaning. It involves our ability to read and understand the words, phrases and sentences.

Benefits of Reading

1. Increases your vocabulary

2. Enhances your imagination

3. Expands your knowledge

4. Stimulates your brain

5. Improves your memory and focus

6. Strengthens your writing skills

7. Helps you to relax and lowers your stress

\section{Micro-skills in Reading}

Micro-skills are the basics skills which are specific competencies for communicating effectively with others. One needs to acquire micro-skills that would help one in the process of reading. Some of them are mentioned below:

1. Understanding the meaning of each words

2. Comprehending the meaning of unfamiliar words from the context.

3. Mastering the basic grammatical units

4. Phonological awareness

5. Orthographic knowledge

\section{Sub-skills of Reading}

Learners need to understand different styles of reading which suits different purposes. For equipping you as an efficient reader, you need to understand the sub-skills of reading. They are:

1. Scanning

2. Skimming

3. Intensive Reading

4. Extensive Reading

\section{Scanning}

When a person search for a particular information, word or phrase it can be called as scanning. It is used to find a specific piece of information. For example, while referring a word in a Dictionary we are adopting the technique of scanning.

More Examples

1. Reading the Newspaper for the Tvprogrammes

2. Referring to a Telephone directory

\section{Skimming}

Skimming is used to quickly gain the overall idea of a passage, book or anything you read. When you skip through a book to get an extract of the book it is called as skimming. When the skimming technique is used we only look at the main headings, sub-headings or illustrations in order to get the overall idea of the content.

Examples:

1. Reading the daily newspaper

2. Reading Brochures

\section{Intensive Reading}

In depth reading for better understanding can be called as intensive reading. Very close and minute details will be included in intensive reading. When you prepare for an examination we thoroughly examine the minute aspects, that is each and everything discussed in the book for better understanding. It is important for you to understand each word, information or fact.

Examples:

1. When you prepare for an examination you have to read intensively for better understanding the concepts or theories.

2. While signing any contract or insurance policy we make a careful reading.

\section{Extensive Reading}

Extensive reading is used to obtain a general understanding of a text or subject. It is mainly used to get some pleasure out of reading that is reading for external purpose. So reading for pleasure to get the main theme of the content can be called as extensive reading. Reading Novels is the best example of extensive reading.

\section{Writing Skill}

Writing skills are an important part of communication. Good writing skills allow you to communicate your message with clarity and ease to a far larger audience than through face-to-face or telephone conversations.

\section{Steps for Writing:}

For developing one as a better writer he/she needs to acquaint with certain steps they are:

\section{Selection of Topic}

The very basic step of writing content is to choose and decide a topic on which you want to write. You can select any topic as you wish according to your convenience. But you need to have a clear understanding of the topic in which you want to write about.

\section{Collection of Information}

After selecting the topic, the next step is to research as much as possible and to collect valid information regarding the topic. Collect all the thoughts, ideas, 
information related to it. Most importantly, research the concerning audience and try to find what they want. Identify the main theme of the content. Make sure that your points are related to main topic.

\section{Organization of Content}

The next step is to organize them in a proper order. Creating an outline of the write up helps in appropriately organizing the content. This can help in the meaningful conveyance of your topic.

\section{Writing}

This is the thrust area for a writer. The choice of words, the division of the paragraphs, the use of headings or subtitles, facts, and figures create a huge impact on the reader's mind. Also, try to put the cause and effect, or comparison and contrast, or problem and solution style of writing.

\section{Revision}

Don't think that the first write up is the final one, as you need to revise your content through constant reading. You can make addition or deletion, or else you can rearrange your subject matter.

\section{Editing and Proof Reading}

Once you finish your writing, the next step is editing, formatting, and proof-reading. For instance, check for spelling, grammar, punctuation, voices, speech, and sentence formation, and other errors.

\section{Final Draft}

This is the last step in writing. Once, the document is ready it is the time for printing or publishing or putting it on a website for readers.

\section{REFERENCES}

[1] Das, Mohan \&Gopakumar, R. (2015). English Language Skills For Communication I. New Delhi: Oxford University Press.

[2] International Listening Association - Home. (n.d.). Retrieved from http://www.listen.org/

[3] Kumar, Sanjay \&LataPushp. (2011). Communication skills. New Delhi: Oxford University Press.

[4] Schwantes, M. (2019, June 14). Here's Tony Robbins' Advice on How to Dramatically Improve Your Communication Skills. Retrieved from https://www.inc.com/marcel-schwantes/heres-tony-robbinsadvice-on-how-to-dramatically-improve-yourcommunication-skills.html

[5] Steps for Writing: Writing Skills with Six Steps of ... (n.d.). Retrieved from https://www.toppr.com/guides/businesscorrespondence-and-reporting/introduction-to-basicwriting/steps-for-writing/
[6] What is Speaking? (n.d.). Retrieved from https://www.englishclub.com/speaking/what-isspeaking.htm

[7] 2011-2021, (. C. (n.d.). Writing Skills. Retrieved from https://www.skillsyouneed.com/writing-skills.html 